\title{
Different doses of steroid injection in elderly patients with carpal tunnel syndrome: a triple- blind, randomized, controlled trial
}

\author{
Reza Salman Roghani ${ }^{1,2}$ \\ Mohammad Taghi Holisaz ${ }^{3}$ \\ Masoud Tarkashvand ${ }^{3}$ \\ Ahmad Delbari ${ }^{4}$ \\ Faeze Gohari ${ }^{2}$ \\ Andrea J Boon ${ }^{5,6}$ \\ Johan Lokk' \\ 'Department of Neurobiology, \\ Care Sciences and Society, Division \\ of Clinical Geriatrics, Karolinska \\ Institutet, Stockholm, Sweden; \\ ${ }^{2}$ Physical Medicine and Rehabilitation \\ Research Center, Shahid Beheshti \\ University of Medical Sciences, \\ ${ }^{3}$ Department of Physical Medicine and \\ Rehabilitation, Baqiyatallah University \\ of Medical Sciences, ${ }^{4}$ Research Center \\ on Aging, University of Social Welfare \\ and Rehabilitation, Tehran, Iran; \\ ${ }^{5}$ Department of Physical Medicine \\ and Rehabilitation, ${ }^{6}$ Department of \\ Neurology, Mayo Clinic, Rochester, \\ MN, USA
}

This article was published in the following Dove Press journal: Clinical Interventions in Aging
Background: Carpal tunnel syndrome (CTS) is commonly seen in elderly populations, in part due to increased presence of predisposing comorbidities as well as physiological changes. We aimed at comparing the effectiveness of different doses of steroid using the ultrasoundguided hydrodissection method in elderly patients with CTS.

Methods: We conducted a prospective, triple-blind, randomized, controlled trial in elderly patients with CTS. Patients were allocated to one of three groups by simplified randomization. Groups I-III received $80 \mathrm{mg}$ triamcinolone $(2 \mathrm{~mL})$ and $1 \mathrm{~mL}$ of $2 \%$ lidocaine; $40 \mathrm{mg}$ triamcinolone $(1 \mathrm{~mL})$, $1 \mathrm{~mL}$ of $2 \%$ lidocaine, and $1 \mathrm{~mL}$ normal saline; and $1 \mathrm{~mL}$ of $2 \%$ lidocaine and $2 \mathrm{~mL}$ normal saline, respectively to make up to $3 \mathrm{~mL}$ volume. A wrist splint was then applied for support. Outcome measures included the visual analog scale (VAS) and the Boston Carpal Tunnel Questionnaire, and median motor and sensory nerve conduction and its sonographic inlet cross-sectional area were used as objective measures. All data were recorded at baseline and 2, 12, and 24 weeks after injection. The investigators, patients, and statistician were blinded to the treatment assignment. Results: In total, 161 patients were recruited without statistically significant demographic differences between the three groups. There were no statistically significant differences between groups in any outcome, with the exception of the median distal motor latency, which was greater in Group II at all three follow-up visits, and significant baseline VAS difference between Groups I and III.

Conclusion: Hydrodissection with lidocaine and normal saline is as effective as hydrodissection with low- and high-dose steroid medication in elderly patients with CTS in this study, but further studies with matched baseline measures and also a sham group are suggested for definitive recommendation.

Keywords: elderly, carpal tunnel syndrome, steroid injection, ultrasonography, hydrodissection, hand pain, paresthesia

\section{Introduction}

Carpal tunnel syndrome (CTS) is the most common entrapment neuropathy, and its incidence and severity have been suggested to increase with age. ${ }^{1-3}$ Based on the World Health Organization, most developed countries in the world have accepted the age of " 65 " years as "elderly", but many studies consider the age of " 60 " as elderly in developing countries. ${ }^{4}$ Lam and Thurston's study indicates that there were significantly more CTS patients aged $>55$ years than in the general population. ${ }^{3}$ In a similar pattern, Vessey et al reported a doubling in the rate of CTS after the age of 50 years. ${ }^{5}$ Another study by Bland and Rudolfer showed a bimodal age distribution with the first peak between the ages of 50 and 54 years and a second peak within $75-84$ years. ${ }^{1}$ Since there
Correspondence: Johan Lokk Department of Neurobiology, Care Sciences and Society, Alfred Nobels allé 23, D3 (Floor 3), Campus Huddinge (Flemingsberg), SE-I4I 83 Huddinge, Sweden

Tel +46858585407

Email johan.lokk@karolinska.se 
is no definite cutoff age for such kind of effect in the case of CTS patients, the cutoff age for elderly discrimination and intervention has significant variance in the literature. ${ }^{1,2,6-9}$

The elderly have a higher prevalence of severe CTS, introduced with the presence of thenar wasting and a severe nerve conduction deficit. ${ }^{1,9-13}$ Blumenthal et al have postulated that there were no age differences in CTS symptoms, hand function, the presence of autonomic symptoms, or the presence of Tinel's or Phalen's sign, ${ }^{7}$ but some other studies reported significant differences. ${ }^{8,9,13}$ Aging per se causes changes in peripheral nerves' structural, physiological, and functional characteristics. ${ }^{14,15}$ If CTS is left untreated, it can lead to long-term disability secondary to permanent median nerve damage. ${ }^{16-18}$ To avoid this permanent sequela, the elderly should be considered as a high-risk group even in the absence of firm clinical evidence.

Elderly persons are also more likely to have coexisting comorbidities such as cardiac disease, hypertension, diabetes mellitus, hypothyroidism, and cervical spondylosis leading to cervical radiculopathy and/or myelopathy, etc. Polypharmacy for managing such multiple comorbidities complicates the clinical picture and may add to physiological changes in the nerve. ${ }^{19}$ Thus, in these patients, it is of particular importance to optimize treatment protocols and, in the case of carpal tunnel injection, to select the optimal dose of medication while minimizing adverse effects. However, the optimal dose is still not defined entirely in younger patients.

Ultrasound-guided hydrodissection is a recently developed treatment method in CTS described by Malone et al. ${ }^{20}$ To the best of our knowledge, there is no study comparing different doses of corticosteroids in elderly CTS patients using this technique. Thus, we sought to run this randomized, controlled trial.

\section{Methods}

\section{Setting and subjects}

The trial design was a prospective, triple-blind, randomized, controlled study in patients aged $>50$ years diagnosed with CTS and referred to the Physical Medicine and Rehabilitation Clinic of University Hospital, Tehran, Iran, during the period 2014-2016. Although the age of 60 years has been adjudged as elderly in Iran, since epidemiologic studies reported growing CTS prevalence after the age of 50 years with suggested bimodal peak ages between 50-54 and 75-84 years and the need for early intervention in elderly; we recruited patients aged $>50$ years. ${ }^{1,3-5}$

Only one physician screened and examined patients for eligibility. Our inclusion criteria were clinical diagnosis of
CTS and electrodiagnostic (EDX) confirmation of moderate CTS: for clinical diagnosis, our physician examined all patients based on the American Academy of Orthopaedic Surgeons Clinical Practice Guideline recommendations. ${ }^{21,22}$ The examiner included a detailed history, personal characteristics, pace activities, and comorbidities of the patients. Accordingly, he conducted a standard sensory examination, manual muscle testing of the upper extremity, and provocative tests, eg, Phalen and compression test and discriminatory tests such as Spurling test for alternative diagnoses. In the EDX part, nerve conduction studies (NCSs) were performed by just one physician with $>10$ years of experience, based on the guidelines of the American Association of Neuromuscular and Electrodiagnostic Medicine for suspected CTS. ${ }^{23}$ The reference values of CTS outlined by Dumitru et al were used. ${ }^{24}$ Only the dominant hand in patients with bilateral CTS was chosen, in order to optimize patients' function.

In order to screen for pure moderate severity in CTS patients, minimizing possible adverse effects of steroids and eliminating confounding factors as much as possible, the following were set as exclusion criteria: 1) severe weakness, requiring carpal tunnel release; 2) a previous history of CTS treatment or injection; 3) corticosteroid or triamcinolone allergy or contraindication; 4) diabetes mellitus, rheumatoid arthritis, thyroid dysfunction, or any severe heart disease, including life-threatening arrhythmia; ${ }^{25} 5$ ) the presence of neurologic disorders such as polyneuropathy, proximal median or ulnar neuropathy, plexopathy, mononeuritis multiplex, and cervical radiculopathy, applying EDX tests.

\section{Measurements}

Demographic data, including age, gender, and medication profile, were recorded. Forearm length, hand length, and wrist diameter were measured, by using a caliper; wrist circumference was measured by using a tape measure. Pain severity and hand force were evaluated at baseline by visual analog scale (VAS) and hand dynamometer, respectively. NCS parameters were evaluated to confirm the diagnosis of moderate CTS as described above. Clinical severity of symptoms was evaluated by using a validated 19-item Boston Carpal Tunnel Questionnaire (BCTQ), including 11-item Symptom Severity Scale and 8-item Functional Status Scale. BCTQ scoring was based on a 1-5 grading scale for each item, meaning "normal" to "very severely affected," respectively. Median nerve inlet cross-sectional area was used as the sonographic outcome measure, being the most sensitive and specific parameter for diagnosing CTS sonographically. ${ }^{26-28}$ Median nerve distal motor latency (median DML) and median nerve sensory nerve 
action potential were recorded as the EDX outcome measures. All data were recorded at baseline, 2 weeks, 3 months, and 6 months after injection. Patients were also asked about the possible adverse effects at each follow-up visit.

\section{Design}

Recruited subjects who met inclusion and exclusion criteria were randomized to one of three groups using a computergeneralized randomization list, and the labeling process was performed by a third person not involved in the project, followed by baseline assessments.

Each patient received a unique code, indicating their assigned group. A study nurse was the only investigator aware of the code, and she prepared the study injection medication out of the sight of the injector and patient in an opaque syringe (covered with white opaque paper) based on the group allocation, immediately before the injection procedure. All syringes contained a total of $3 \mathrm{~mL}$ of injectate for the hydrodissection. Group I received $80 \mathrm{mg}$ triamcinolone ( $2 \mathrm{~mL}$ ) and $1 \mathrm{~mL}$ of $2 \%$ lidocaine; Group II received 40 $\mathrm{mg}$ triamcinolone $(1 \mathrm{~mL}), 1 \mathrm{~mL}$ of $2 \%$ lidocaine, and $1 \mathrm{~mL}$ normal saline; Group III received $1 \mathrm{~mL}$ of $2 \%$ lidocaine and $2 \mathrm{~mL}$ normal saline. ${ }^{20}$ However, lidocaine per se has been suggested to provide some beneficial results because of its anti-inflammatory effects, ${ }^{29-33}$ and steroids are often mixed with this local anesthetic to reduce pain during injection in order to make patients tolerant to dissection's pain during the injection and after discharge. We also tried to eliminate such probable confounding effects by unifying its dosage across the study groups. In all the groups, a wrist splint for support was administered immediately after the injection.

Atroshi et al evaluated the effectiveness of methylprednisolone, ${ }^{34}$ but we tried triamcinolone because it was more accessible in our market at that time; however, it is less soluble and has longer lasting effects, less rapid effect, and more subcutaneous fat atrophy. ${ }^{35} \mathrm{We}$ did the injection carefully in order to not pass the injectate further than the proximal edge of the flexor retinaculum, applying pressure in the most proximal part of the sonography probe during injection and closing the trajectory at the time of withdrawal and for a while after that.

The Esaote ultrasound system (MyLab ${ }^{\mathrm{TM}}-25$; Esaote, Genoa, Italy) with $10-18 \mathrm{MHz}$ multidimensional linear-array transducer was employed in the study. Study subjects were positioned supine, with the forearm in relaxed supination and the wrist in slight dorsiflexion. The ultrasound probe was placed perpendicular to the distal wrist crease, parallel to the anatomical sagittal axis. The proximal border was placed on the radiolunate joint at the volar aspect of the forearm. Then, the distal border was set about $1 \mathrm{~cm}$ distal to the distal wrist crease, at the distal end of the capitate bone. After adjusting the probe, identifying the maximal nerve diameter (Figure 1), and skin preparation, a 26-gauge needle was introduced into the palmar surface of the hand applying in-plane approach. After passage beneath the distal edge of the flexor retinaculum, the drug was injected gradually, and the needle was advanced proximally toward the level of the radioulnar joint, dissecting the flexor retinaculum away from the median nerve via gradual drug infiltration, and trying not to pass the proximal part of the flexor retinaculum by advancing the needle gradually and compressing the proximal part of the probe. At the end of the injection, prior to withdrawing the needle, the physician covered the skin over the needle entry site with sterile gauze, closing the trajectory and remaining blinded, in case of medication leakage. ${ }^{20,25}$

\section{Ethical issues and registration}

The trial was performed in full compliance with the Declaration of Helsinki after acquiring approval from the Ethics Review Board of the Baqiyatallah University of Medical Sciences (No 34-13). The trial was registered in IRCT.ir (Identifier Number: IRCT2014020416485N1). All subjects
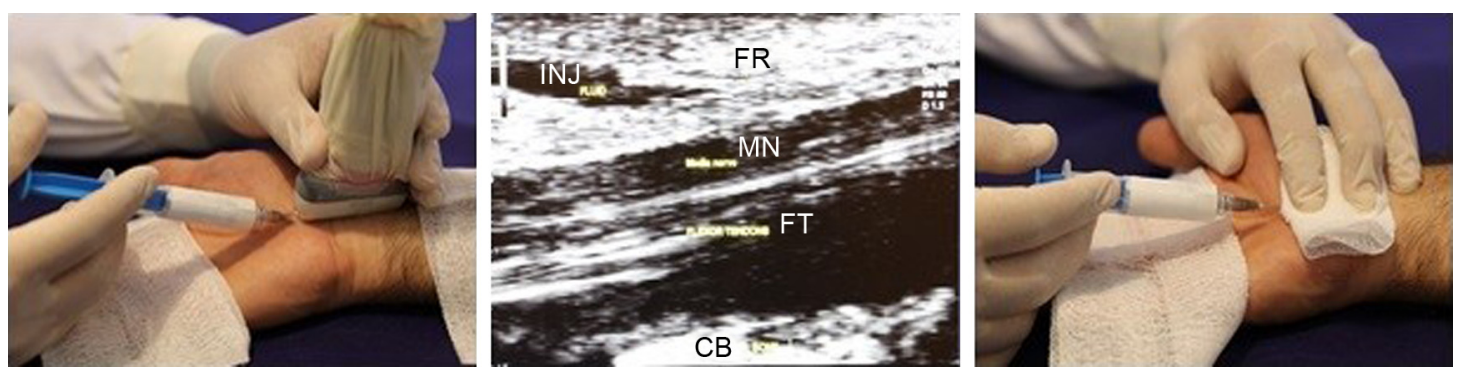

Figure I Sonography, injection, and blinding for injector.

Note: The syringe was covered by a sterile opaque white paper (left picture); flexor retinaculum (FR), median nerve (MN), and the injectate (INJ) for dissection are shown in the middle picture; covering the needle at the time of withdrawal (right picture).

Abbreviations: FT, flexor tendon; $\mathrm{CB}$, carpal bone. 
were informed of the study objectives, options for CTS treatment, and potential side effects of hydrodissection with local steroid injection, including hypopigmentation, subcutaneous atrophy, and possible median nerve injury. ${ }^{20,25}$ Written informed consent was received from all the patients.

\section{Sample size}

Considering a total success rate of $70 \%$ for local steroid injection, based on a review by Jeremy Bland, ${ }^{36}$ with an absolute precision of 0.2 , the final sample size was estimated to be at least 21 subjects per group. The power and the significance level were set at 0.8 and 0.05 , respectively. Jeremy Bland considered the last two responses from worth/no effect/ slightly better/much better/cured, as equivalent to success after CTS treatment. ${ }^{36}$

\section{Statistical analysis}

All statistical analyses were performed by using IBM SPSS Statistics, Version 19.0 (SPSS Inc., Chicago, IL, USA), and the patients were included in the analysis according to the intention-to-treat principle. Descriptive statistics were used to summarize the data, representing medians and ranges with nonparametric data, while the mean and standard deviation were employed using parametric data. Distribution of data was tested using the Kolmogorov-Smirnov test. An $\alpha<0.05$ was considered significant. Repeated-measures analysis of variance (ANOVA), followed by Tukey's post hoc testing and its nonparametric equivalent, Friedman, was used to compare quantitative variables among the three treatment groups before the study intervention and at the follow-up visits. To compare the demographic variables, a one-way ANOVA test was applied.

\section{Results}

A total of 161 consecutive patients were screened during the study period, of whom 18 did not meet the inclusion criteria, 27 declined to participate, and 14 met the exclusion criteria. The remaining 102 patients were randomly allocated to three intervention groups. Of these, 94 patients completed the entire study course and were analyzed. Two subjects in Group I, three subjects in Group II, and three subjects in Group III withdrew during the course of the study. These dropouts did not wish to explain the reason for their withdrawal during a subsequent telephone follow-up. However, they denied any side effects of the injection and any complication. Figure 2 illustrates the study flow chart.

Table 1 presents the demographic data of the participants. There were no statistical differences between the groups. Table 2 presents descriptive data on primary outcome measures at different follow-up points, together with the

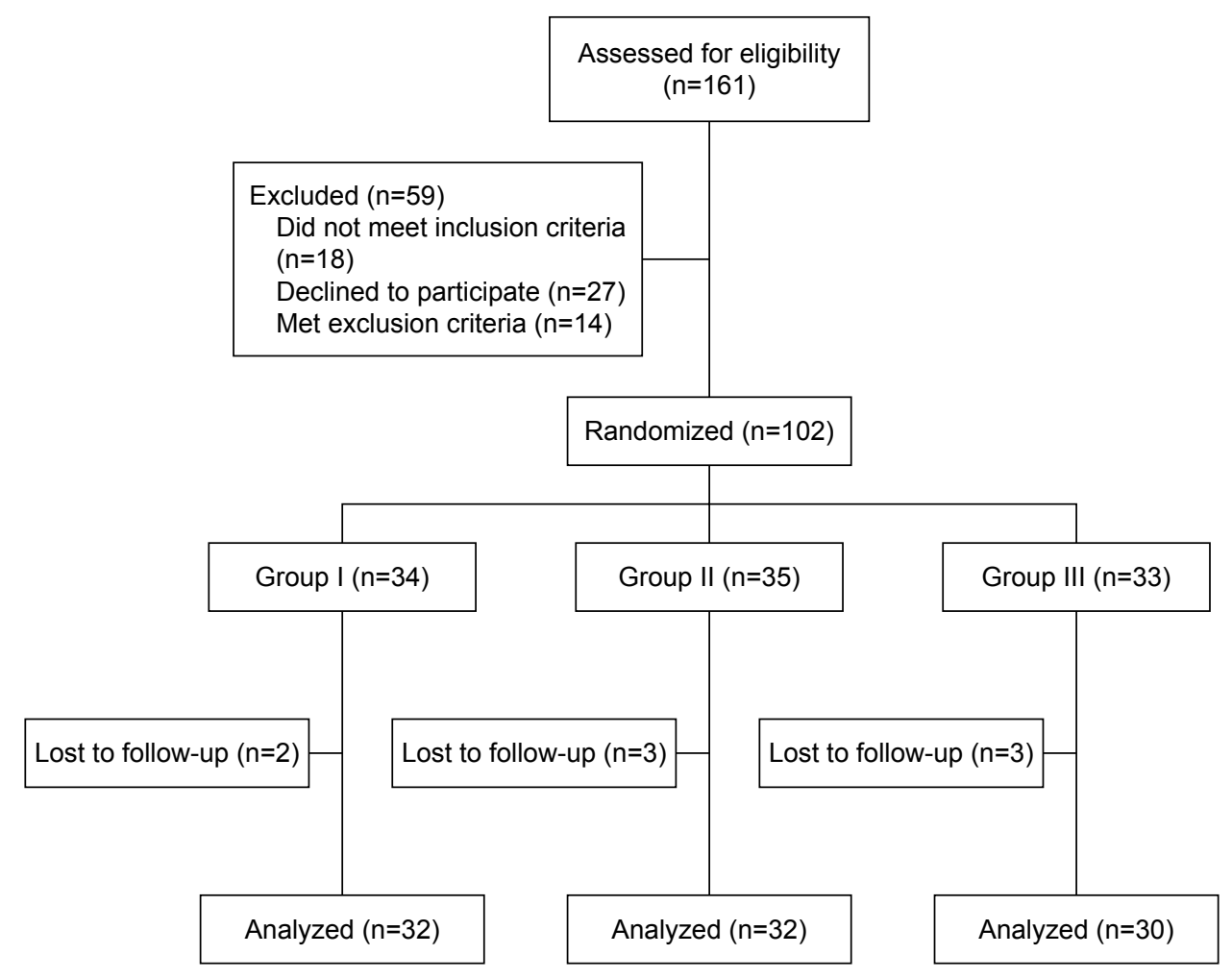

Figure 2 Study flowchart.

Note: Group I received $80 \mathrm{mg}$ triamcinolone $(2 \mathrm{~mL})$ and I $\mathrm{mL}$ of $2 \%$ lidocaine; Group II received $40 \mathrm{mg}$ triamcinolone $(\mathrm{I} \mathrm{mL})$, I mL of $2 \%$ lidocaine, and I mL normal saline; Group III received I $\mathrm{mL}$ of $2 \%$ lidocaine and $2 \mathrm{~mL}$ normal saline. 
Table I Patients' demographics

\begin{tabular}{|c|c|c|c|c|}
\hline Variables & $\begin{array}{l}\text { Group I } \\
(n=32)\end{array}$ & $\begin{array}{l}\text { Group II } \\
(n=32)\end{array}$ & $\begin{array}{l}\text { Group III } \\
(n=30)\end{array}$ & $p$-value \\
\hline Gender (male/female) & $10 / 22$ & $4 / 28$ & $3 / 27$ & 0.057 \\
\hline Age (years) (mean $\pm S D)$ & $66.1 \pm 13.4$ & $66 \pm 10$ & $63.4 \pm 10.7$ & 0.645 \\
\hline Affected hand (right/left) & $18 / 14$ & $16 / 16$ & $19 / 11$ & 0.57 \\
\hline $\begin{array}{l}\text { Affected hand } \\
\text { (dominant/nondominant) }\end{array}$ & $19 / 13$ & $16 / 16$ & $19 / 11$ & 0.549 \\
\hline $\begin{array}{l}\text { Wrist circumstance }(\mathrm{cm}) \\
(\text { mean } \pm \text { SD) }\end{array}$ & $17.2 \pm 1.3$ & $\mid 7 \pm 1$ & $17 \pm 1$ & 0.726 \\
\hline $\begin{array}{l}\text { Wrist diameter }(\mathrm{mm}) \\
(\text { mean } \pm \mathrm{SD})\end{array}$ & $59.8 \pm 3.9$ & $59.7 \pm 4.2$ & $59.8 \pm 3.7$ & 0.991 \\
\hline $\begin{array}{l}\text { Hand length }(\mathrm{cm}) \\
(\text { mean } \pm \text { SD) }\end{array}$ & $17.5 \pm 1.3$ & $17.5 \pm 1.1$ & $17.3 \pm 0.8$ & $0.80 \mathrm{I}$ \\
\hline $\begin{array}{l}\text { Forearm length }(\mathrm{cm}) \\
(\text { mean } \pm \mathrm{SD})\end{array}$ & $23.1 \pm 1.5$ & $23.3 \pm 1.3$ & $23 \pm 1.5$ & 0.618 \\
\hline $\begin{array}{l}\text { Hand power }(\mathrm{kg}) \\
(\text { mean } \pm S D)\end{array}$ & $20.1 \pm 8.1$ & $23.6 \pm 8.4$ & $19.1 \pm 7.5$ & 0.06 \\
\hline
\end{tabular}

Note: Group I received $80 \mathrm{mg}$ triamcinolone $(2 \mathrm{~mL})$ and I $\mathrm{mL}$ of $2 \%$ lidocaine; Group II received $40 \mathrm{mg}$ triamcinolone $(\mathrm{I} \mathrm{mL}), \mathrm{I} \mathrm{mL}$ of $2 \%$ lidocaine, and I $\mathrm{mL}$ normal saline; Group III received I $\mathrm{mL}$ of $2 \%$ lidocaine and $2 \mathrm{~mL}$ normal saline. Abbreviation: SD, standard deviation.

within-group effects. Variables with a normal distribution ( $p$-value $>0.05$ ) were marked with an asterisk. Although we have not matched the groups based on the baseline primary outcome measurements, no significant differences between groups' baseline primary outcomes were detected, except for the VAS measure, in which post hoc analysis revealed a significant difference between baseline VAS scores in Groups I and III. Table 3 presents the normal distribution of the primary outcome measures. In all the three groups, there were significant improvements in symptom score, sonographic measures, and electrophysiologic measures with the sole exception of the median DML in Group III, which decreased over the follow-up period, but not to a statistically significant level. A Scheffe post hoc analysis revealed differences in median DML between Groups II and III, with higher values in Group II ( $p$-value $=0.049)$.

\section{Discussion}

In this study, the efficacy of hydrodissection using two different doses of steroid and one dose of lidocaine was compared in elderly patients with moderate CTS. The results showed a significant within-group trend in a symptomatic improvement in almost all clinical, EDX, and ultrasonographic outcomes, with no statistically significant difference between groups. The only exception was median DML, in which post hoc analysis revealed a borderline difference between Groups II and III, with higher values for the former, making us suggest further investigations into this topic.

The high prevalence of CTS, which has been suggested to increase with age, potential for functional impairment with the associated impact on the quality of life due to permanent axonal loss, and the cost of surgery in severe cases highlight the need for proper management, especially in the elderly. ${ }^{37-39}$ Although, Lam and Thurston and Vessey et al's studies have suggested a significant higher prevalence of CTS over 55 and 50 years, respectively, and Bland and Rudolfer reported a bimodal peak prevalence for CTS between the ages of 50-54 and 75-84 years, the controversy about the cutoff age has not yet been resolved. ${ }^{1,3,5}$ Therefore, cutoff age for elderly discrimination has significant variance in the literature. A prospective study of Porter et al found that the symptoms

Table 2 Outcome measures at baseline and follow-up

\begin{tabular}{|c|c|c|c|c|c|c|}
\hline $\begin{array}{l}\text { Primary outcome } \\
\text { measure }\end{array}$ & $\begin{array}{l}\text { Treatment } \\
\text { group }\end{array}$ & Baseline & $\begin{array}{l}\text { 2-week } \\
\text { follow-up }\end{array}$ & $\begin{array}{l}\text { 3-month } \\
\text { follow-up }\end{array}$ & $\begin{array}{l}\text { 6-month } \\
\text { follow-up }\end{array}$ & $\begin{array}{l}\text { Friedman } \\
\text { test }\end{array}$ \\
\hline \multirow[t]{3}{*}{ VAS (mean $\pm S D)$} & Group I $(n=32)$ & $7.29 \pm 2.05 *$ & $4.24 \pm 2.09 *$ & $4.15 \pm 2.21 *$ & $2.43 \pm 1.93^{*}$ & $<0.001$ \\
\hline & Group II (n=32) & $6.22 \pm 2.74^{*}$ & $4.8 \mathrm{I} \pm 2.39 *$ & $3.23 \pm 2.03 *$ & $2 \pm 1.44$ & $<0.001$ \\
\hline & Group III $(n=30)$ & $5.8 \pm 1.88 *$ & $4.2 \pm 1.75^{*}$ & $3.19 \pm 2.12^{*}$ & $2.75 \pm 2.56$ & $<0.001$ \\
\hline Median DML & Group I (n=32) & $5.08 \pm 1.35^{*}$ & $4.70 \pm 1.2 *$ & $4.55 \pm 1.12 *$ & $4.32 \pm 0.66^{*}$ & 0.001 \\
\hline \multirow[t]{2}{*}{$($ mean $\pm S D)$} & Group II (n=32) & $5.15 \pm 1.23$ & $5.00 \pm 1.23 *$ & $4.80 \pm 1.23 *$ & $4.65 \pm 0.8 *$ & $<0.001$ \\
\hline & Group III $(n=30)$ & $4.69 \pm I .5 I^{*}$ & $4.50 \pm 1.32 *$ & $4.45 \pm 1.19 *$ & $4.16 \pm 0.7 *$ & 0.887 \\
\hline Median SNAP & Group I $(n=32)$ & $4.05 \pm 1.55$ & $3.73 \pm 1.5$ & $3.80 \pm 1.39$ & $4.04 \pm 0.75^{*}$ & 0.01 \\
\hline \multirow[t]{2}{*}{$($ mean $\pm S D)$} & Group II (n=32) & $3.28 \pm 2.2$ & $3.24 \pm 1.94$ & $3.7 I \pm I .68$ & $4.05 \pm I .5 I^{*}$ & 0.025 \\
\hline & Group III $(n=30)$ & $3.90 \pm 1.15$ & $3.80 \pm 1.18^{*}$ & $3.96 \pm 0.93^{*}$ & $3.86 \pm 0.36^{*}$ & 0.037 \\
\hline Inlet CSA & Group I $(n=32)$ & $11.73 \pm 2.53^{*}$ & $10.77 \pm 2.18^{*}$ & $10.78 \pm 2.39 *$ & $10.45 \pm 2.37^{*}$ & 0.002 \\
\hline \multirow[t]{2}{*}{$($ mean $\pm S D)$} & Group II (n=32) & $12.23 \pm 2.49 *$ & $11.55 \pm 2.4^{*}$ & $11.26 \pm 2.19^{*}$ & $10.26 \pm 2.34^{*}$ & $<0.001$ \\
\hline & Group III $(n=30)$ & $12.09 \pm 3.96^{*}$ & $11.23 \pm 2.72 *$ & $11.37 \pm 1.97 *$ & $10.76 \pm 2.05^{*}$ & 0.007 \\
\hline Boston & Group I $(n=32)$ & $55.8 I \pm 15.04^{*}$ & $41.95 \pm 11.26 *$ & $40.43 \pm 12.14^{*}$ & $34.06 \pm 10.25 *$ & 0.001 \\
\hline \multirow[t]{2}{*}{$($ mean $\pm S D)$} & Group II (n=32) & $47.70 \pm 11.70 *$ & $44.94 \pm 9.70^{*}$ & $43.41 \pm 10.97 *$ & $38.67 \pm|| .21 *$ & $<0.001$ \\
\hline & Group III $(n=30)$ & $45.22 \pm 13.84^{*}$ & $40.45 \pm 11.08^{*}$ & $41.27 \pm 12.65^{*}$ & $36.94 \pm 13.04 *$ & 0.018 \\
\hline
\end{tabular}

Notes: *Test distribution is normal. Group I received $80 \mathrm{mg}$ triamcinolone $(2 \mathrm{~mL})$ and I $\mathrm{mL}$ of $2 \%$ lidocaine; Group II received $40 \mathrm{mg}$ triamcinolone (I $\mathrm{mL})$, I $\mathrm{mL}$ of $2 \%$ lidocaine, and I mL normal saline; Group III received I $\mathrm{mL}$ of $2 \%$ lidocaine and $2 \mathrm{~mL}$ normal saline. Bold variable represents a significant difference between groups after treatment.

Abbreviations: CSA, cross-sectional area; DML, distal motor latency; VAS, visual analog scale; SD, standard deviation; SNAP, sensory nerve action potential. 
Table 3 Between-group analyses

\begin{tabular}{ll}
\hline $\begin{array}{l}\text { Primary } \\
\text { outcome }\end{array}$ & $\begin{array}{l}\text { Repeated measurement } \\
\text { ANOVA (between group) }\end{array}$ \\
\hline VAS & 0.399 \\
Median DML & $\mathbf{0 . 0 3}$ \\
Inlet CSA & 0.512 \\
Boston & 0.756 \\
\hline
\end{tabular}

Note: Bold variable represents a significant difference between groups after treatment.

Abbreviations: ANOVA, analysis of variance; CSA, cross-sectional area; DML, distal motor latency; VAS, visual analog scale.

and function improvement decreases after operation in the elderly; they chose a cutoff age of 60 years without any explanation. ${ }^{9}$ Stone et al showed that, even with the cutoff age of 80 years, the functional outcome and patients' satisfaction rate after decompression were similar to the younger control group ( $<80$ years old), though the elderly are more likely to have thenar muscle atrophy and a severe nerve conduction deficit. ${ }^{13}$ In another study by Hobby et al using five age-groups, patients aged between 60-69 were similar to younger patients' symptoms and functions evaluated with BCTQ score, postoperatively. However, some evidence of poorer outcomes in patients aged $>70$ years was also concluded; the authors finally declared that outcomes are less predictable in patients aged $>70$ years. ${ }^{8}$ However, no study evaluated the effect of age on postinjection outcomes in elderly patients with CTS.

Furthermore, elderly patients usually have more comorbidities, such as cardiac disease, diabetes mellitus, and hypertension, hence they are affected by higher complication rates when receiving surgery or higher doses of steroids. Recent meta-analyses have shown that corticosteroid injections diminish symptom severity and improve function in comparison with placebo. ${ }^{40,41}$ However, steroids are often mixed with local anesthetics to reduce pain postinjection, among which lidocaine is the most commonly used agent. ${ }^{33}$ Adverse effects of steroids on diabetes mellitus and hypertension must be taken into consideration when electing to treat patients with steroids. Consequently, nonsteroid injections in elderly patients may be a reasonable choice due to less adverse effects. Lidocaine produces local anesthesia through selective blockade of $\mathrm{A} \delta$ and $\mathrm{C}$ nerve fibers. It also produces vasodilatation, modulated by endothelial cell secreted nitrous oxide, through simultaneous blockade of sodium channels. ${ }^{42}$ A systematic review suggested that lidocaine has a potential role as an anti-inflammatory agent. ${ }^{29}$ It has been postulated that the inhibition of nuclear factor- $\mathrm{\kappa B}$ through the phosphorylation of p 38 mitogen active protein kinase by lidocaine can account for the anti-inflammatory effects, ${ }^{30-32}$ and this could be a potential explanation for the results observed in Group III, where only lidocaine, and no steroid, was administered. However, without a sham group, it could not concluded as a real effect to differentiate it from placebo effect.

The pathophysiology of CTS is not completely understood. Increased pressure, either by adhesion caused by noninflammatory fibrosis of subsynovial connective tissue surrounding the median nerve ${ }^{43}$ or by a volume increase within the carpal tunnel, as well as flexor tendon synovial connective tissue adhesion around the median nerve, is a possible etiology. ${ }^{44}$ Hydrodissection itself may address the adhesions, separating the nerve from the surrounding tissues. To our knowledge, there are no prior studies comparing different corticosteroid doses in combination with hydrodissection in elderly patients. Dernek et a ${ }^{45}$ studied 67 CTS patients diagnosed on the basis of physical examination and NCSs. Some received a blend of $0.5 \mathrm{~mL}$ normal saline solution and $0.5 \mathrm{~mL}$ lidocaine, while the rest received $1 \mathrm{~mL}$ betamethasone dipropionate. Results showed that there were no significant differences between groups at baseline and 1-, 3-, and 6-month postinjection follow-ups in VAS or Quick Disabilities of the Arm, Shoulder, and Hand scores. Consequently, the authors suggested lidocaine injection was an excellent alternative to corticosteroid injection, without potential side effects. ${ }^{45}$ Another randomized, placebocontrolled trial by Karadas et al in CTS patients was conducted in 2012. They enrolled 57 CTS patients, who were assigned to one of three groups: group 1 received $1 \mathrm{~mL}$ $0.09 \%$ normal saline, group 2 received $40 \mathrm{mg}$ triamcinolone acetonide, and group 3 received $4 \mathrm{~mL} \mathrm{1 \%}$ procaine $\mathrm{HCl}$. The same degree of improvement was observed in groups 2 and 3, but not in group 1 at the 2- and 6-month postinjection follow-ups.$^{46}$ Lack of blinded design and applying a different volume of injection in different groups were limitations of that study, however. We chose not to have a placebo group in our study, to avoid pain related to high-volume injections, with a potential detrimental impact on patient recruitment and preventing study approval by our ethics committee.

Some studies suggest that local anesthetic should be used in CTS patients in whom steroids are contraindicated, eg, those with severe diabetes mellitus and hypertension. ${ }^{46}$ Vahi et al pointed out in their study that postoperative complications were more common in those with multiple preoperative steroid injections. ${ }^{47}$ However, the Bland and Ashworth study refuted that the prior local steroid injection can prejudice the outcome of surgery ${ }^{48}$ Consequently, in cases where surgical intervention may be indicated or has to be delayed, lidocaine injection might be more appropriate than steroid injection, especially in the elderly. 
Strengths of this study included the use of a gold standard approach to the clinical diagnosis; the use of outcome measures such as the BCTQ, NCSs, and ultrasound parameters; and the inclusion of relatively long-term follow-up. Further methodological strengths of the study are that outcome was assessed prospectively in a consecutive series of patients with almost complete follow-up. Our study did not compare the results of the elderly with younger patients, nor include a true placebo group and an untreated/sham control group. Another major limitation of our study was the restricted follow-up time of about 6 months, rather than 12 months. We also did not match the groups regarding baseline measurements, and the base line analysis showed up with a significant difference for VAS between Groups I and III in post hoc analysis, which may be a source of error in the final conclusion, though other measures have no significant difference at baseline.

\section{Conclusion}

Ultrasound-guided hydrodissection of the median nerve with either lidocaine and steroid or lidocaine alone may be efficacious and safe in the treatment of moderate CTS in elderly patients, especially in those with severe comorbidities where steroids can not be used. However, further investigation, considering baseline measures matching and comparing to a sham placebo group, is needed in order for definitive recommendations to be made.

\section{Disclosure}

The authors report no conflicts of interest in this work.

\section{References}

1. Bland JD, Rudolfer SM. Clinical surveillance of carpal tunnel syndrome in two areas of the United Kingdom, 1991-2001. J Neurol Neurosurg Psychiatry. 2003;74(12):1674-1679.

2. Seror P. Carpal tunnel syndrome in the elderly. "Beware of severe cases". Ann Chir Main Memb Super. 1991;10(3):217-225.

3. Lam N, Thurston A. Association of obesity, gender, age and occupation with carpal tunnel syndrome. Aust N Z J Surg. 1998;68(3):190-193.

4. Noroozian M. The elderly population in Iran: an ever growing concern in the health system. Iran J Psychiatry Behav Sci. 2012;6(2):1-6.

5. Vessey MP, Villard-Mackintosh L, Yeates D. Epidemiology of carpal tunnel syndrome in women of child bearing age: findings in a large cohort study. Int J Epidemiol. 1990;19(3):655-659.

6. National Center for Health Statistics. Health, United States, 2006 With Chartbook on Trends in the Health of Americans. Hyattsville, MD; 2006. Available from: https://www.cdc.gov/nchs/data/hus/hus06.pdf

7. Blumenthal S, Herskovitz S, Verghese J. Carpal tunnel syndrome in older adults. Muscle Nerve. 2006;34(1):78-83.

8. Hobby JL, Venkatesh R, Motkur P. The effect of age and gender upon symptoms and surgical outcomes in carpal tunnel syndrome. J Hand Surg Br. 2005;30(6):599-604.

9. Porter P, Venkateswaran B, Stephenson H, Wray CC. The influence of age on outcome after operation for the carpal tunnel syndrome. A prospective study. J Bone Joint Surg Br. 2002;84(5):688-691.
10. Weber RA, Rude MJ. Clinical outcomes of carpal tunnel release in patients 65 and older. J Hand Surg Am. 2005;30(1):75-80.

11. Townshend DN, Taylor PK, Gwynne-Jones DP. The outcome of carpal tunnel decompression in elderly patients. J Hand Surg Am. 2005;30(3):500-505.

12. Leit ME, Weiser RW, Tomaino MM. Patient-reported outcome after carpal tunnel release for advanced disease: a prospective and longitudinal assessment in patients older than age 70. J Hand Surg Am. 2004; 29(3):379-383.

13. Stone OD, Clement ND, Duckworth AD, Jenkins PJ, Annan JD, McEachan JE. Carpal tunnel decompression in the super-elderly: functional outcome and patient satisfaction are equal to those of their younger counterparts. Bone Joint J. 2014;96-B(9):1234-1238.

14. Kovacic U, Sketelj J, Bajrovic FF. Chapter 26: age-related differences in the reinnervation after peripheral nerve injury. Int Rev Neurobiol. 2009;87:465-482.

15. Verdu E, Ceballos D, Vilches JJ, Navarro X. Influence of aging on peripheral nerve function and regeneration. J Peripher Nerv Syst. 2000; 5(4):191-208.

16. Padua L, Coraci D, Erra C, et al. Carpal tunnel syndrome: clinical features, diagnosis, and management. Lancet Neurol. 2016;15(12):1273-1284.

17. Barcenilla A, March LM, Chen JS, Sambrook PN. Carpal tunnel syndrome and its relationship to occupation: a meta-analysis. Rheumatology (Oxford). 2012;51(2):250-261.

18. Alfonso C, Jann S, Massa R, Torreggiani A. Diagnosis, treatment and follow-up of the carpal tunnel syndrome: a review. Neurol Sci. 2010;31(3):243-252.

19. Kanatani T, Nagura I, Kurosaka M, Kokubu T, Sumi M. Electrophysiological assessment of carpal tunnel syndrome in elderly patients: one-year follow-up study. J Hand Surg Am. 2014;39(11):2188-2191.

20. Malone DG, Clark TB, Wei N. Ultrasound-guided percutaneous injection, hydrodissection, and fenestration for carpal tunnel syndrome: description of a new technique. J Appl Res. 2010;10(3):117.

21. Sucher BM, Schreiber AL. Carpal tunnel syndrome diagnosis. Phys Med Rehabil Clin N Am. 2014;25(2):229-247.

22. Keith MW, Masear V, Chung KC, et al. American Academy of Orthopaedic Surgeons Clinical Practice Guideline on diagnosis of carpal tunnel syndrome. J Bone Joint Surg Am. 2009;91(10):2478-2479.

23. Jablecki CK, Andary MT, Floeter MK, et al. Practice parameter: electrodiagnostic studies in carpal tunnel syndrome. Report of the American Association of Electrodiagnostic Medicine, American Academy of Neurology, and the American Academy of Physical Medicine and Rehabilitation. Neurology. 2002;58(11):1589-1592.

24. Dumitru D, Amato A, Zwarts M. Electrodiagnostic Medicine. 2nd ed. Philadelphia, USA: Hanley \& Belfus, Inc.; 2002.

25. Preston DC, Shapiro BE. Electromyography and Neuromuscular Disorders. Clinical-Electrophysiologic Correlations. 3rd ed. Elsevier Inc.; 2013.

26. Beekman R, Visser LH. Sonography in the diagnosis of carpal tunnel syndrome: a critical review of the literature. Muscle Nerve. 2003;27(1):26-33.

27. Roll SC, Case-Smith J, Evans KD. Diagnostic accuracy of ultrasonography vs. electromyography in carpal tunnel syndrome: a systematic review of literature. Ultrasound Med Biol. 2011;37(10):1539-1553.

28. Tai TW, Wu CY, Su FC, Chern TC, Jou IM. Ultrasonography for diagnosing carpal tunnel syndrome: a meta-analysis of diagnostic test accuracy. Ultrasound Med Biol. 2012;38(7):1121-1128.

29. Caracas HC, Maciel JV, Martins PM, de Souza MM, Maia LC. The use of lidocaine as an anti-inflammatory substance: a systematic review. J Dent. 2009;37(2):93-97.

30. Lee PY, Tsai PS, Huang YH, Huang CJ. Inhibition of toll-like receptor-4, nuclear factor-kappaB and mitogen-activated protein kinase by lignocaine may involve voltage-sensitive sodium channels. Clin Exp Pharmacol Physiol. 2008;35(9):1052-1058.

31. Su D, Gu Y, Wang Z, Wang X. Lidocaine attenuates proinflammatory cytokine production induced by extracellular adenosine triphosphate in cultured rat microglia. Anesth Analg. 2010;111(3):768-774. 
32. Wang HL, Zhang WH, Lei WF, Zhou CQ, Ye T. The inhibitory effect of lidocaine on the release of high mobility group box 1 in lipopolysaccharide-stimulated macrophages. Anesth Analg. 2011;112(4):839-844.

33. Hyvonen PM, Kowolik MJ. Dose-dependent suppression of the neutrophil respiratory burst by lidocaine. Acta Anaesthesiol Scand. 1998;42(5):565-569.

34. Atroshi I, Flondell M, Hofer M, Ranstam J. Methylprednisolone injections for the carpal tunnel syndrome: a randomized, placebo-controlled trial. Ann Intern Med. 2013;159(5):309-317.

35. Jacobs JW, Michels-van Amelsfort JM. How to perform local soft-tissue glucocorticoid injections? Best Pract Res Clin Rheumatol. 2013;27(2): 171-194.

36. Bland JD. Treatment of carpal tunnel syndrome. Muscle Nerve. 2007; 36(2):167-171.

37. Klauser AS, Halpern EJ, De Zordo T, et al. Carpal tunnel syndrome assessment with US: value of additional cross-sectional area measurements of the median nerve in patients versus healthy volunteers. Radiology. 2009;250(1):171-177.

38. Descatha A, Huard L, Duval S. Letter to the editor: the sensitivity and specificity of ultrasound for the diagnosis of carpal tunnel syndrome: a meta-analysis. Clin Orthop Relat Res. 2011;469(3):901-902; author reply 903-904.

39. Fowler JR, Gaughan JP, Ilyas AM. The sensitivity and specificity of ultrasound for the diagnosis of carpal tunnel syndrome: a meta-analysis. Clin Orthop Relat Res. 2011;469(4):1089-1094.

40. Chen PC, Chuang CH, Tu YK, Bai CH, Chen CF, Liaw M. A Bayesian network meta-analysis: Comparing the clinical effectiveness of local corticosteroid injections using different treatment strategies for carpal tunnel syndrome. BMC Musculoskelet Disord. 2015;16:363.
41. Chen PC, Chuang CH. [The effectiveness of different corticosteroid injections in patients with carpal tunnel syndrome: a Bayesian network meta-analysis]. Hu Li Za Zhi. 2016;63(3):73-82. Chinese.

42. Roberson DP, Binshtok AM, Blasl F, Bean BP, Woolf CJ. Targeting of sodium channel blockers into nociceptors to produce long-duration analgesia: a systematic study and review. Br J Pharmacol. 2011; 164(1):48-58.

43. Ettema AM, Amadio PC, Zhao C, Wold LE, An KN. A histological and immunohistochemical study of the subsynovial connective tissue in idiopathic carpal tunnel syndrome. J Bone Joint Surg Am. 2004; 86-A(7):1458-1466.

44. Deger AN, Deger H, Taser F. The role of neoangiogenesis and vascular endothelial growth factor in the development of carpal tunnel syndrome in patients with diabetes. Niger J Clin Pract. 2016;19(2):189-195.

45. Dernek B, Aydin T, Koseoglu PK, et al. Comparison of the efficacy of lidocaine and betamethasone dipropionate in carpal tunnel syndrome injection. J Back Musculoskelet Rehabil. 2017;30(3):435-440.

46. Karadas O, Tok F, Akarsu S, Tekin L, Balaban B. Triamcinolone acetonide vs procaine hydrochloride injection in the management of carpal tunnel syndrome: randomized placebo-controlled study. J Rehabil Med. 2012;44(7):601-604.

47. Vahi PS, Kals M, Koiv L, Braschinsky M. Preoperative corticosteroid injections are associated with worse long-term outcome of surgical carpal tunnel release. Acta Orthop. 2014;85(1):102-106.

48. Bland JD, Ashworth NL. Does prior local corticosteroid injection prejudice the outcome of subsequent carpal tunnel decompression? J Hand Surg Eur Vol. 2016;41(2):130-136.
Clinical Interventions in Aging

\section{Publish your work in this journal}

Clinical Interventions in Aging is an international, peer-reviewed journal focusing on evidence-based reports on the value or lack thereof of treatments intended to prevent or delay the onset of maladaptive correlates of aging in human beings. This journal is indexed on PubMed Central, MedLine,

\section{Dovepress}

CAS, Scopus and the Elsevier Bibliographic databases. The manuscript management system is completely online and includes a very quick and fair peer-review system, which is all easy to use. Visit http://www.dovepress. com/testimonials.php to read real quotes from published authors. 